\title{
Strategy for Balancing Interests of Business, Government and Society in the Field of International Trade in the Digital Economy
}

\author{
Ihor Nestoryshen ${ }^{1}$, Yevhenii Rudnichenko ${ }^{2}$, Serhii Shevchuk ${ }^{3}$, Liudmyla Oliynyk ${ }^{4}$, \\ Nataliia Havlovska ${ }^{2}$, Liudmyla Bohatchyk ${ }^{2}$ \\ ${ }^{1}$ Research Institute of Fiscal Policy, University of State Fiscal Service of Ukraine, Khmelnitsky, Ukraine \\ ${ }^{2}$ Khmelnitsky National University, Khmelnitsky, Ukraine \\ ${ }^{3}$ University of State Fiscal Service of Ukraine, Irpin, Ukraine \\ ${ }^{4}$ Vinnytsia Educational-Research Institute of National University of State Fiscal Service of Ukraine, \\ Vinnytsia, Ukraine
}

\begin{abstract}
Global control of business by a state causes a conflict of interests and additional barriers to the development of international trade, which necessitates the formation of an appropriate strategy for balanced relations between business and society in the digital economy. Taking into account the main provisions of the agency theory, the choice of an effective strategy for interaction between state institutions and FEA participants requires the adoption of an effective toolkit for estimating such interaction. Using the main provisions of game theory, the study developed a corresponding game model, which includes three participants: state, economic operators, society. Based on the modelling of relevant processes, it was concluded that a state has 80 pure strategies, economic operators have 20 pure strategies, and society has 5 pure strategies, while results of a current game make it possible to determine the most advantageous situation of interaction for a state and economic operators.
\end{abstract}

DOI: 10.18421/TEM104-11

https://doi.org/10.18421/TEM104-11

Corresponding author: Yevhenii Rudnichenko, Khmelnitsky National University, Khmelnitsky, Ukraine. Email: e.m.rudnichenko@gmail.com

Received: 04 May 2021.

Revised: 23 September 2021.

Accepted: 29 September 2021.

Published: 26 November 2021.

(c) BY-NC-ND 2021 Ihor Nestoryshen et al; published by UIKTEN. This work is licensed under the Creative Commons Attribution-NonCommercial-NoDerivs 4.0 License.

The article is published with Open Access at www.temjournal.com
Thus, from the standpoint of regulating international trade, the issues of forming a balance of interests of all participants in this process allow to obtain positive results not only for specific business entities, but also for society as a whole.

Keywords - strategy, international trade, digital economy, balance of interests, game theory, model

\section{Introduction}

Transformations in the global economic space predetermine the need for appropriate changes in the field of international trade. As WCO Chairman K. Mikuriya noted, the creation of a simultaneously favourable, safe, fair and sustainable environment should be attributed to the priority tasks of customs administrations, helping enterprises, especially micro, small and medium-sized ones, to expand their field of activity and create preconditions for more active participation in global trade. We are talking about the formation of a "reliable" business environment from the point of view of the customs sphere, which is based on "security", "fairness" and "sustainability". The defining direction for creating a favourable business environment in accordance with the recommendations of the World Customs Organization is the process of further simplification of customs procedures for entities with a high degree of trust, fighting corruption and facilitating the movement of goods, vehicles and people in general.

However, in practice, a kind of conflict of interests often arises between state, business community and society due to the increased influence of regulation of the sphere of international trade [3].

With a total strengthening of control, there is a risk of a decrease in the foreign economic activity of business entities, and this, in turn, leads to a tangible economic recession, a decrease in tax and customs revenues to a state budget, and an increase in social tension in society. 
Thus, in the context of the implementation of a balanced mechanism for ensuring economic security, the issues of modelling the processes of overcoming the contradictions of all interested parties to ensure security and simplification of customs procedures, as well as stimulating the development of international trade in the digital economy are being actualized.

We should note that the conflict nature and diversity of economic interests at different levels of their implementation by all participants determine that the economic security of a state is not an invariable, static state, but it can be ensured only in dynamics, in constant change by combining different, conflicting interests, determining ways for their solution. In addition, unlike other areas of government regulation (tax, investment, financial, labour), government regulation of foreign trade is largely determined by the requirements and recommendations of international organizations (WTO, WCO, etc.), whose activities are aimed at creating common approaches, methods, principles, rules of customs regulation in order to prevent obstacles to the development of international trade.

That is why the system of relations of economic interests in the field of FEA "business-communitystate-society" should take into account the guidelines and recommendations of international organizations to ensure the security of the international supply chain, because the inconsistency of national standards with international ones significantly limits the opportunities for equal participation of domestic business in the international supply chain.

The interaction of economic interests of business, state and society is a multilevel and complex system. A system of relations "business-state-society" is formed in conditions of significant influence of the recommendations of international organizations on compliance with norms and standards of customs control.

Aspects of the formation and implementation of the concept of balance of interests were studied by many scientists, in particular in the twentieth century a significant number of theories appeared. They are devoted to the search for a balance of interests, game theory [8], theory of balance of interests at the state level [9], antagonism in concepts of balance of interests and national interest [1]. The research of D. Campbell, who developed the theory of real conflict [13], which made it possible to more fully comprehend the concept of "balance of interests" in society, is of particular relevance in this context. According to his theory, intergroup conflicts are generated by the same factors as interpersonal conflicts of interest between groups.

Since the interaction of business, state and society often occurs in conditions of uncertainty, fuzzy sets, utility theory, game theory can be used in modelling according to the specifics of the tools' choice, and, given the antagonistic nature and strategic direction of interaction of the above entities, the most acceptable for modelling such interaction is game theory. Regarding the application of game theory in modern economic research, we must agree with the following point of view [12]: game theory proves that if players do not change their strategy, sooner or later they will come to an equilibrium state in which the gain can no longer be increased by continuing to follow the chosen course of action. There are only two types of such equilibrium states in the game (and several subspecies follow from them) - Nash equilibrium [4], [5] and Pareto principle [6], [7]. Application of game theory to solve a wide range of problems is also considered in the works by Ukrainian scientists [2], [11] who explore the specifics of interaction between government institutions and business entities, as well as search for optimal strategies for such interaction in the medium and long term.

\section{Research Method}

The interaction of interests of FEA participants can be modelled only with a clear list of parties to the interaction. Such parties are (let's accept conditional names): state; economic operators (this is a set of economic operators that are indirectly or directly united by a specific purpose - profit and stability, first of all); society (for a more concise statement - in reality, society here represents trade unions, public associations, non-profit organizations, institutions, etc., which have indirect or direct links with foreign institutions).

This list is presented in the order of conditional potential strength of the foreign trade participant's influence on the results of foreign economic activity and related processes (which, of course, due to their connection with foreign economic activity have a significant impact on the country's economy as a whole). A state, economic operators and society are such participants in foreign economic activity, which in pairwise interaction comprehensively characterize and form foreign economic activity as a process.

Thus, our game model will include three participants [2], [15]. In game theory, they are also called players or parties to the interaction. However, the best option here would be the "participant" and, sometimes, to prevent the tautology - the "party", as it would be ambiguous to call "player" society, a set of economic operators or, moreover, a state.

Further, in order to model the interaction of FEA participants, it is also necessary to determine the list of components of the net strategies of each of the participants. These components of strategies are in fact the levers by which the participant exerts its influence on the end result of such interaction. And this result is usually different from the results of other participants [10], [14]. 
On the part of a state, it is necessary to identify four areas in which it is possible to conduct foreign economic activity and partially control its course (the full control, when everything depends only on the decisions of a state is impossible): 1) tariff regulation; 2) non-tariff regulation measures; 3 ) plan for additional mobilization of customs payments by customs; 4) providing simplifications under the program of the authorized economic operator.

Control over the course of foreign trade in tariff regulation is carried out on two levers: 1.1) establishment or exemption from customs duties; 1.2) determining the rate of import (export) duty, excise tax, VAT.

It should be noted that non-tariff regulation measures are not related to the application of customs duties on goods moving across the customs border, established in accordance with the law prohibitions and / or restrictions aimed at protecting the internal market, public order and safety, public morality, protection of health and life of humans and animals, protection of natural environment, protection of rights of consumers of goods imported into a country, as well as protection of national cultural and historical heritage. Control over the course of foreign economic activity by non-tariff regulation is carried out on three levers: 2.1) ban on import (export) of goods of certain groups to (from) a country; 2.2) establishment of quotas for import (export) of goods of certain groups to (from) a country; 2.3) hidden measures of non-tariff regulation (technical barriers: national standards and requirements to goods).

So, a state owns seven levers that affect the result of interaction between foreign economic activity participants. Before providing a characteristic of the numerical estimates of these levers, let us try to determine the type of these estimates. In order to mention these levers, we have: 1) establishment / exemption from customs taxation - obviously, there should be either 1 (established duty) or 0 (exempt from customs taxation); 2) determination of size of duty rate - this lever is valid only when the duty is established, and its value is invested in a certain interval from the minimum to the maximum. For the sake of maintaining compatibility, we will assume the minimum value as 0 , which will correspond to exemption from customs taxation. We will return to the maximum value of this lever later; 3) ban on import / export of goods, as well as the establishment or exemption from customs taxation, will have a discrete numerical characteristic: 1 will comply with a ban, 0 - no ban; 4) establishment of quotas for import / export of goods - this lever is valid only in the absence of just mentioned ban. That is why the values of quotas will be placed in a certain interval from minimum to maximum, where the minimum value will be equal to 0 , which will correspond to the established prohibition. The maximum value of quotas, as well as the size of the duty rate, depends on a number of factors. We will return to this assessment later; 5) covert measures of non-tariff regulation - in the first (and simplest) approximation, this lever can also be considered "discrete": 0 will mean the absence of any covert measures, 1 will mean that such measures are present; 6) plan for additional mobilization of customs payments by the customs of the SFS of Ukraine is similarly "discrete": 0 will mean the absence of such a plan or its inapplicability (for various reasons), 1 will mean that such a plan is available and, moreover, applicable. However, of course, it should be noted that in the absence of this plan, customs payments will be made "by default"; 7) providing simplifications under the program of the authorized economic operator again, in the first approximation, we have a "discrete" lever, where 0 means no simplifications, 1 means that such simplifications are provided (without specifying the list of these simplifications so far).

On the part of economic operators, two very important levers, which directly affect the interaction of FEA participants should be identified: 1) FEA of a given economic operator or group of economic operators; 2) choice of type and form of FEA.

In the simplest case, the foreign economic activity could be measured discretely (roughly speaking, 1 delivery of goods, 0 - no delivery). However, here nothing will prevent us from assessing of foreign economic activity on a percentage scale, where $100 \%$ corresponds to the maximum possible activity. However, in the future this scale will still be transformed into a more universal type.

For economic operators, the choice of the type and form of foreign economic activity means the choice of the form of cooperation with foreign partners. For example, these are import, export, toll manufacturing, offshore. Therefore, the assessment of this leverage should be typically discrete. We will encode the appropriate forms of cooperation using integers (natural) numbers: 1 - import, 2 - export, 3 - toll manufacturing, 4 - offshore, and so on, if there is a need for further numbering.

Within the framework of our research and in the context of balancing the interests of all participants in foreign economic activity, society is considered as potential consumers of products, the availability of which directly or indirectly depends on the results of concluding foreign economic activity agreements. Here, there are only two possibilities arising from the intention, in fact, to buy or not to buy: 1) buy goods from official importers; 2) buy goods through ecommerce opportunities (including international mail and international express mail).

At the same time, it should be emphasized that in the context of the COVID-19 pandemic, the share of goods sold using digital technologies on the network is increasing significantly. So, it is necessary to take into account the conditions of the digital economy. 
Thus, in our game model, a state (the first participant) has more opportunities for choice - seven components of a pure strategy, two of which (determining the size of the duty rate and establishing quotas on the import / export of goods) are actually continuous, that is, they can take any value in within certain intervals. The rest (five components of a pure strategy) are discrete (even binary) and can take only two values ( 1 or 0$)$.

Economic operators (they represent the second participant) have two components of pure strategy. The level of foreign economic activity of a given economic operator (a group of economic operators) is undoubtedly a continuous component. The type and form of FEA implementation is an exclusively discrete component, but it is not a binary component. Here the number of possible integer values (coded forms of cooperation) can be arbitrary, but there should be not less than four of them.

Society as a third party has one pure strategy that is continuous. It can be presented in the form of a unit interval, where 1 will correspond to the fact that the goods are purchased from official importers. In general, the value of this interval indicates a conditional share of goods purchased from official importers. When approaching 0 , the share of purchased goods through the possibilities of Internet commerce will grow. In other words, a value of 0 will correspond to a state in which all goods are purchased through the possibilities of Internet commerce.

Let us denote the component of the pure strategy of a state under the number $i$ by $d_{i}$ and, following the numbering given in the previous subsection:

$$
\mathbf{D}=\left[d_{1} d_{2} d_{3} d_{4} d_{5} d_{6} d_{7}\right]
$$

So, there is a generalized pure strategy of a state. Of course, the components of strategy (1) have their own limitations, which were already mentioned above. Let us comment on these restrictions, noting immediately that we are moving on to the dimensionless values of these seven components.

First of all, the establishment / exemption from customs taxation will be described as $d_{1} \in\{0,1\}$. It is clear that $d_{1}=1$ will mean the establishment of customs taxation, $d_{1}=0$ exemption from customs duties.

As mentioned above, the minimum possible value for $d_{1}$ equals 0 . Maximum value for $d_{2}$ due to the transition to dimensionless values will be equal to 1 . So, $d_{2} \in[0 ; 1]$. However, the limitation here is the following:

$$
\begin{aligned}
& \text { if } d_{1}=1, \text { then } d_{2} \in[0 ; 1], \\
& \text { but if } d_{1}=0, \text { then } d_{2}=0 \text { always. }
\end{aligned}
$$

Establishment of quotas on import / export of goods $\left(d_{4}\right)$ expressed in the same dimensionless quantity within a unit interval: $d_{4} \in[0 ; 1]$. As well as in case with $d_{1}$ and $d_{2}$, there is a limit on the value of the component $d_{4}$, formed by the ban on the import / export of goods (i.e., value $d_{3}$ ). In this case:

$$
\text { if } d_{3}=1 \text {, then always } d_{4}=0 \text {, }
$$

$$
\text { but if } d_{3}=0 \text {, then } d_{4} \in[0 ; 1] \text {. }
$$

Further, the rest of the components are similar to $d_{1}$ and $d_{3}: d_{5} \in\{0,1\}, d_{6} \in\{0,1\}, d_{7} \in\{0,1\}$.

What 0 and 1 values of these components mean has already been discussed in the previous section.

Since the pure strategy of economic operators consists of two components, let $r_{l}$ be the level of activity of foreign economic activity of a given economic operator (group of economic operators) from 0 (lowest level) to 1 (highest level of activity). Accordingly, $r_{2}$ denotes the choice of the type and form of implementation of foreign economic activity. Thus, the pure strategy of economic operators:

$$
\begin{aligned}
& \mathbf{R}=\left[r_{1} r_{2}\right] \text { with } r_{1} \in[0 ; 1] \\
& \text { and } r_{2} \in\{1,2,3,4, \ldots, Q\} .
\end{aligned}
$$

Where $Q$ - the total number of types and forms of FEA for this group of economic operators.

We denote the near strategy of society as $s$, where $s \in[0 ; 1]$. The value of $s$ is equal to the notional share of goods purchased from official importers, and the value of $1-s$ is equal to the notional share of goods purchased through e-commerce.

Thus, the game model of interaction of three FEA participants is an endless non- cooperative game of three players. Therefore, the winning function of each participant depends on 10 values:

$$
d_{1}, d_{2}, d_{3}, d_{4}, d_{5}, d_{6}, d_{7}, r_{1}, r_{2}, s .
$$

Of course, the construction of each such function in analytical form is impossible, because in the general case it is unknown how the interval values of variables:

$$
d_{2}, d_{4}, r_{1}, s
$$

affect the values of the winning functions. That is, the presence of an infinite set of possible values of the variable in this case makes it impossible to record the gain function in analytical form.

\section{Results}

First of all, we note that any function from 10 variables (5) is an extremely complex reflection of these variables on a subset of real numbers, regardless of whether there are intervals among the variables (5), they are all represented by a finite set of possible values. Since it is impossible to analytically determine the payoff function of each participant in foreign economic activity through the interval values of variables (6), these variables must be discretized. Step 0.5 is too large and rough, and step 0.1 gives 11 possible values $(0,0.1,0.2,0.3, \ldots$, $0.9,1)$, which is redundant from a practical point of view. Therefore, a step of 0.25 is the most rational and acceptable to start with. According to this step, formulas (2), (3) and (4) can be rewritten as follows: 
if $d_{1}=1$, then $d_{2} \in\{0,0.25,0.5,0.75,1\}$, but if $d_{1}=0$, then $d_{2}=0$ always;

if $d_{3}=1$, then $d_{4}=0$ always, but if $d_{3}=0$, then $d_{4} \in\{0,0.25,0.5,0.75,1\}$;

$\mathbf{R}=\left[\begin{array}{ll}r_{1} & r_{2}\end{array}\right]$ with $r_{1} \in\{0,0.25,0.5,0.75,1\}$ and $r_{2} \in\{1,2,3,4, \ldots, Q\}$.
I strategy of society also takes a simplified form:

$$
s \in\{0,0.25,0.5,0.75,1\} .
$$

Thus, now a state has at its disposal a finite number of possible options for action on the levers, which will influence the outcome of the interaction of participants in foreign economic activity. This number would seem to be 800 (Figure 1.).

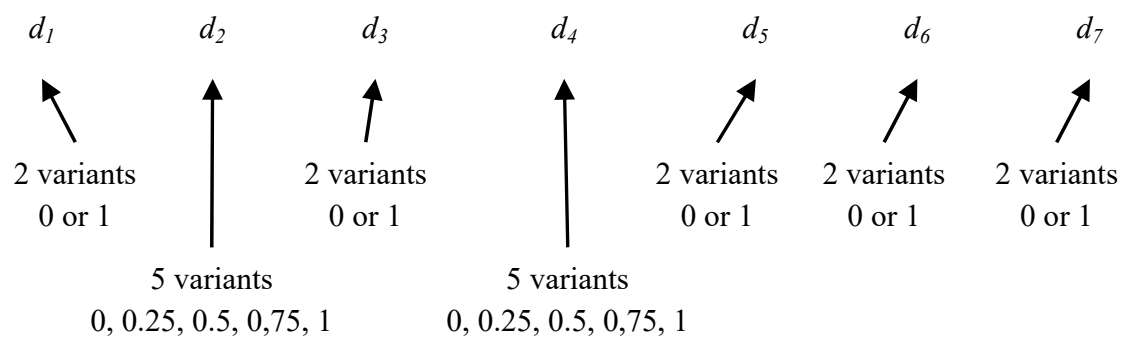

Figure 1. The fictitiously exaggerated number of possible options for action on levers by a state is equal to $2 \cdot 5 \cdot 2 \cdot 5 \cdot 2 \cdot 2 \cdot 2=800$

But here it is necessary to take into account the exceptions in formulas (7) and (8), when the exemption from duty means 0 duty rate, and the ban on import / export of goods corresponds to 0 quotas on import / export of goods. Therefore, it is obvious that the actual number of possible options for action by a state will be smaller.

Figure 2. shows the program code for calculating this number. This code is easily adjusted to new conditions for determining the actual number of options for action by a state.

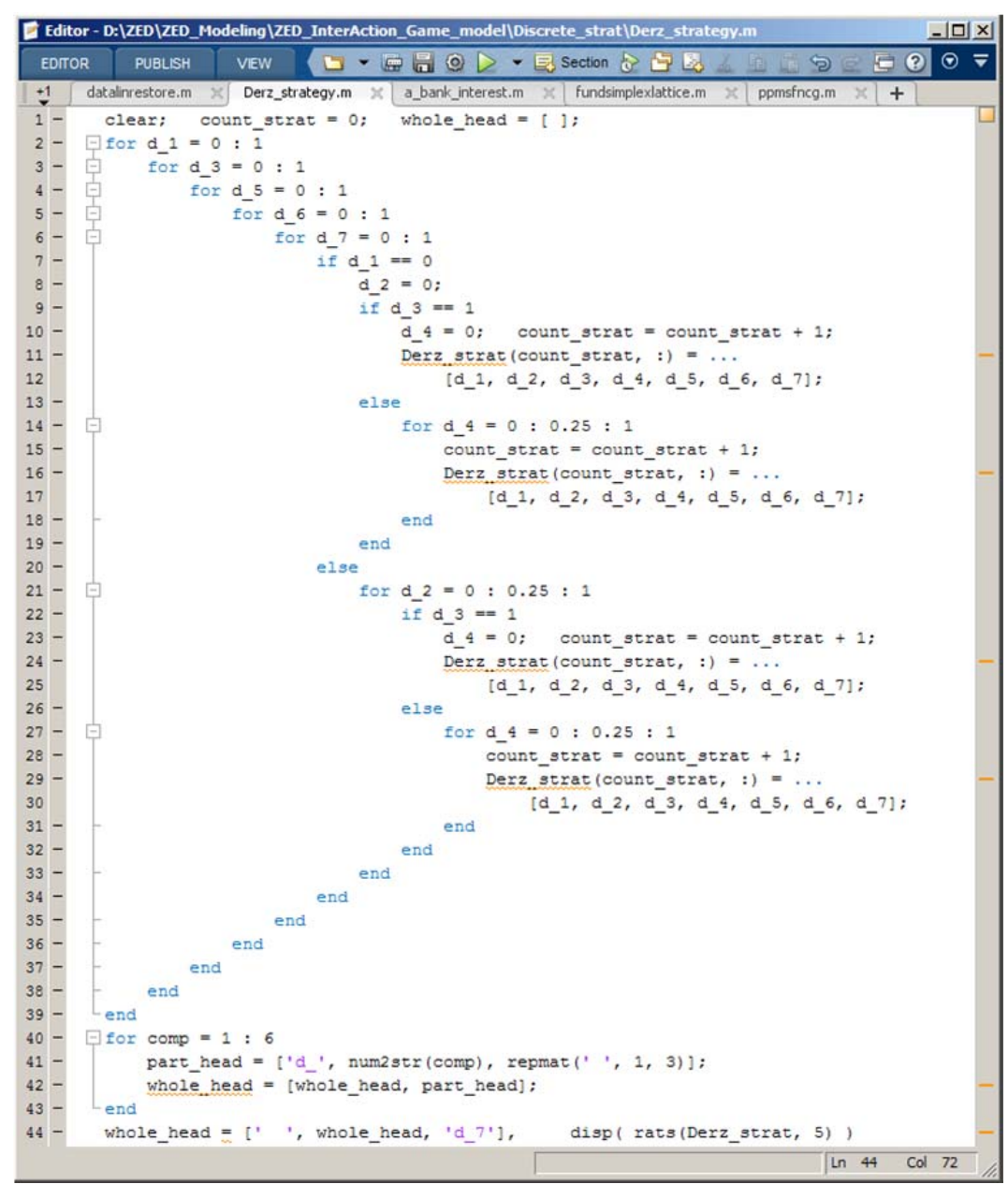

Figure 2. Code of the program procedure in the MATLAB environment for determining the actual number of possible options for action on levers by a state 
After executing the code of the program procedure in Figure 2., it turns out that a state has 288 strategies. Partially possible strategies are presented in Figure 3., taking into account the variables in (1).

$\begin{array}{lccccccc} & \text { d_1 } & d-2 & d-3 & d-4 & d-5 & d-6 & d_{-7}^{7} \\ 139 . & 1 & 3 / 4 & 0 & 0 & 0 & 1 & 1 \\ 140 . & 1 & 3 / 4 & 0 & 1 / 4 & 0 & 1 & 1 \\ 141 . & 1 & 3 / 4 & 0 & 1 / 2 & 0 & 1 & 1 \\ 142 . & 1 & 3 / 4 & 0 & 3 / 4 & 0 & 1 & 1 \\ 143 . & 1 & 3 / 4 & 0 & 1 & 0 & 1 & 1 \\ 144 . & 1 & 1 & 0 & 0 & 0 & 1 & 1 \\ 145 . & 1 & 1 & 0 & 1 / 4 & 0 & 1 & 1 \\ 146 . & 1 & 1 & 0 & 1 / 2 & 0 & 1 & 1 \\ 147 . & 1 & 1 & 0 & 3 / 4 & 0 & 1 & 1 \\ 148 . & 1 & 1 & 0 & 1 & 0 & 1 & 1 \\ 149 . & 1 & 0 & 0 & 0 & 1 & 0 & 0 \\ 150 . & 1 & 0 & 0 & 1 / 4 & 1 & 0 & 0 \\ 151 . & 1 & 0 & 0 & 1 / 2 & 1 & 0 & 0 \\ 152 . & 1 & 0 & 0 & 3 / 4 & 1 & 0 & 0 \\ 153 . & 1 & 0 & 0 & 1 & 1 & 0 & 0 \\ 154 . & 1 & 1 / 4 & 0 & 0 & 1 & 0 & 0 \\ 155 . & 1 & 1 / 4 & 0 & 1 / 4 & 1 & 0 & 0 \\ 156 . & 1 & 1 / 4 & 0 & 1 / 2 & 1 & 0 & 0 \\ 157 . & 1 & 1 / 4 & 0 & 3 / 4 & 1 & 0 & 0 \\ 158 . & 1 & 1 / 4 & 0 & 1 & 1 & 0 & 0 \\ 159 . & 1 & 1 / 2 & 0 & 0 & 1 & 0 & 0 \\ 160 . & 1 & 1 / 2 & 0 & 1 / 4 & 1 & 0 & 0 \\ 161 . & 1 & 1 / 2 & 0 & 1 / 2 & 1 & 0 & 0 \\ 162 . & 1 & 1 / 2 & 0 & 3 / 4 & 1 & 0 & 0 \\ 163 . & 1 & 1 / 2 & 0 & 1 & 1 & 0 & 0 \\ 164 . & 1 & 3 / 4 & 0 & 0 & 1 & 0 & 0 \\ 165 . & 1 & 3 / 4 & 0 & 1 / 4 & 1 & 0 & 0 \\ 166 . & 1 & 3 / 4 & 0 & 1 / 2 & 1 & 0 & 0 \\ 167 . & 1 & 3 / 4 & 0 & 3 / 4 & 1 & 0 & 0 \\ 168 . & 1 & 3 / 4 & 0 & 1 & 1 & 0 & 0 \\ 169 . & 1 & 1 & 0 & 0 & 1 & 0 & 0 \\ 170 . & 1 & 1 & 0 & 1 / 4 & 1 & 0 & 0 \\ 171 . & 1 & 1 & 0 & 1 / 2 & 1 & 0 & 0 \\ 172 . & 1 & 1 & 0 & 3 / 4 & 1 & 0 & 0 \\ 173 . & 1 & 1 & 0 & 1 & 1 & 0 & 0 \\ 174 . & 1 & 0 & 0 & 0 & 1 & 0 & 1 \\ 175 . & 1 & 0 & 0 & 1 / 4 & 1 & 0 & 1 \\ 176 . & 1 & 0 & 0 & 1 / 2 & 1 & 0 & 1 \\ 177 . & 1 & 0 & 0 & 3 / 4 & 1 & 0 & 1 \\ 178 . & 1 & 0 & 0 & 1 & 1 & 0 & 1 \\ 179 . & 1 & 1 / 4 & 0 & 0 & 1 & 0 & 1 \\ 180 . & 1 & 1 / 4 & 0 & 1 / 4 & 1 & 0 & 1 \\ 181 . & 1 & 1 / 4 & 0 & 1 / 2 & 1 & 0 & 1 \\ 182 . & 1 & 1 / 4 & 0 & 3 / 4 & 1 & 0 & 1 \\ 183 . & 1 & 1 / 4 & 0 & 1 & 1 & 0 & 1 \\ 184 . & 1 & 1 / 2 & 0 & 0 & 1 & 0 & 1 \\ 185 . & 1 & 1 / 2 & 0 & 1 / 4 & 1 & 0 & 1 \\ 186 . & 1 & 1 / 2 & 0 & 1 / 2 & 1 & 0 & 1 \\ 187 . & 1 & 1 / 2 & 0 & 3 / 4 & 1 & 0 & 1 \\ 188 . & 1 & 1 / 2 & 0 & 1 & 1 & 0 & 1\end{array}$

\begin{tabular}{|c|c|c|c|c|c|c|c|}
\hline 189. & $\overline{1}$ & $3 / 4$ & $\overline{0}$ & $\overline{0}$ & $\overline{1}$ & $\overline{0}$ & 1 \\
\hline 190. & 1 & $3 / 4$ & 0 & $1 / 4$ & 1 & 0 & 1 \\
\hline 191. & 1 & $3 / 4$ & 0 & $1 / 2$ & 1 & 0 & \\
\hline 192. & 1 & $3 / 4$ & 0 & $3 / 4$ & 1 & 0 & \\
\hline 193. & 1 & $3 / 4$ & 0 & 1 & 1 & 0 & \\
\hline 194. & 1 & 1 & 0 & 0 & 1 & 0 & \\
\hline 195. & 1 & 1 & 0 & $1 / 4$ & 1 & 0 & \\
\hline 196. & 1 & 1 & 0 & $1 / 2$ & 1 & 0 & \\
\hline 197. & 1 & 1 & 0 & $3 / 4$ & 1 & 0 & \\
\hline 198. & 1 & 1 & 0 & 1 & 1 & 0 & \\
\hline 199. & 1 & 0 & 0 & 0 & 1 & 1 & \\
\hline 200. & 1 & 0 & 0 & $1 / 4$ & 1 & 1 & \\
\hline 201. & 1 & 0 & 0 & $1 / 2$ & 1 & 1 & \\
\hline 202 . & 1 & 0 & 0 & $3 / 4$ & 1 & 1 & \\
\hline 203. & 1 & 0 & 0 & 1 & 1 & 1 & \\
\hline 204. & 1 & $1 / 4$ & 0 & 0 & 1 & 1 & \\
\hline 205. & 1 & $1 / 4$ & 0 & $1 / 4$ & 1 & 1 & \\
\hline 206. & 1 & $1 / 4$ & 0 & $1 / 2$ & 1 & 1 & \\
\hline 207. & 1 & $1 / 4$ & 0 & $3 / 4$ & 1 & 1 & \\
\hline 208. & 1 & $1 / 4$ & 0 & 1 & 1 & 1 & b \\
\hline 209. & 1 & $1 / 2$ & 0 & 0 & 1 & 1 & 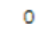 \\
\hline 210 . & 1 & $1 / 2$ & 0 & $1 / 4$ & 1 & 1 & \\
\hline 211. & 1 & $1 / 2$ & 0 & $1 / 2$ & 1 & 1 & \\
\hline 212. & 1 & $1 / 2$ & 0 & $3 / 4$ & 1 & 1 & b \\
\hline 213. & 1 & $1 / 2$ & 0 & 1 & 1 & 1 & 0 \\
\hline 214. & 1 & $3 / 4$ & 0 & 0 & 1 & 1 & 0 \\
\hline 215. & 1 & $3 / 4$ & 0 & $1 / 4$ & 1 & 1 & 0 \\
\hline 216. & 1 & $3 / 4$ & 0 & $1 / 2$ & 1 & 1 & 0 \\
\hline 217 . & 1 & $3 / 4$ & 0 & $3 / 4$ & 1 & 1 & 0 \\
\hline 218. & 1 & $3 / 4$ & 0 & 1 & 1 & 1 & 0 \\
\hline 219. & 1 & 1 & 0 & 0 & 1 & 1 & b \\
\hline 220. & 1 & 1 & 0 & $1 / 4$ & 1 & 1 & b \\
\hline 221. & 1 & 1 & 0 & $1 / 2$ & 1 & 1 & b \\
\hline 222 . & 1 & 1 & 0 & $3 / 4$ & 1 & 1 & 0 \\
\hline 223. & 1 & 1 & 0 & 1 & 1 & 1 & 0 \\
\hline 224 . & 1 & 0 & 0 & 0 & 1 & 1 & 1 \\
\hline 225 . & 1 & 0 & 0 & $1 / 4$ & 1 & 1 & 1 \\
\hline 226. & 1 & 0 & 0 & $1 / 2$ & 1 & 1 & \\
\hline 227 . & 1 & 0 & 0 & $3 / 4$ & 1 & 1 & 1 \\
\hline 228 . & 1 & 0 & 0 & 1 & 1 & 1 & 1 \\
\hline 229. & 1 & $1 / 4$ & 0 & 0 & 1 & 1 & 1 \\
\hline 230. & 1 & $1 / 4$ & 0 & $1 / 4$ & 1 & 1 & \\
\hline 231. & 1 & $1 / 4$ & 0 & $1 / 2$ & 1 & 1 & \\
\hline 232 . & 1 & $1 / 4$ & 0 & $3 / 4$ & 1 & 1 & 1 \\
\hline 233. & 1 & $1 / 4$ & 0 & 1 & 1 & 1 & \\
\hline 234 . & 1 & $1 / 2$ & 0 & 0 & 1 & 1 & \\
\hline 235. & 1 & $1 / 2$ & 0 & $1 / 4$ & 1 & 1 & \\
\hline 236. & 1 & $1 / 2$ & 0 & $1 / 2$ & 1 & 1 & \\
\hline 237. & 1 & $1 / 2$ & 0 & $3 / 4$ & 1 & 1 & \\
\hline 238. & 1 & $1 / 2$ & 0 & 1 & 1 & 1 & \\
\hline
\end{tabular}

\begin{tabular}{|c|c|c|c|c|c|c|c|}
\hline 239. & 1 & $3 / 4$ & 0 & 0 & 1 & 1 & 1 \\
\hline 240 . & 1 & $3 / 4$ & 0 & $1 / 4$ & 1 & 1 & \\
\hline 241 . & 1 & $3 / 4$ & 0 & $1 / 2$ & 1 & 1 & 1 \\
\hline 242 . & 1 & $3 / 4$ & 0 & $3 / 4$ & 1 & 1 & \\
\hline 243. & 1 & $3 / 4$ & 0 & 1 & 1 & 1 & \\
\hline 244. & 1 & 1 & 0 & 0 & 1 & 1 & \\
\hline 245 . & 1 & 1 & 0 & $1 / 4$ & 1 & 1 & \\
\hline 246. & 1 & 1 & 0 & $1 / 2$ & 1 & 1 & \\
\hline 247 . & 1 & 1 & 0 & $3 / 4$ & 1 & 1 & \\
\hline 248 . & 1 & 1 & 0 & 1 & 1 & 1 & \\
\hline 249. & 1 & 0 & 1 & 0 & 0 & 0 & 0 \\
\hline 250. & 1 & $1 / 4$ & 1 & 0 & 0 & 0 & 0 \\
\hline 251. & 1 & $1 / 2$ & 1 & 0 & 0 & 0 & 0 \\
\hline 252 . & 1 & $3 / 4$ & 1 & 0 & 0 & 0 & 0 \\
\hline 253. & 1 & 1 & 1 & 0 & 0 & 0 & 0 \\
\hline 254 . & 1 & 0 & 1 & 0 & 0 & 0 & 1 \\
\hline 255. & 1 & $1 / 4$ & 1 & 0 & 0 & 0 & 1 \\
\hline 256 . & 1 & $1 / 2$ & 1 & 0 & 0 & 0 & 1 \\
\hline 257 . & 1 & $3 / 4$ & 1 & 0 & 0 & 0 & 1 \\
\hline 258 . & 1 & 1 & 1 & 0 & 0 & 0 & 1 \\
\hline 259 . & 1 & 0 & 1 & 0 & 0 & 1 & 0 \\
\hline 260. & 1 & $1 / 4$ & 1 & 0 & 0 & 1 & 0 \\
\hline 261. & 1 & $1 / 2$ & 1 & 0 & 0 & 1 & 0 \\
\hline 262 . & 1 & $3 / 4$ & 1 & 0 & 0 & 1 & 0 \\
\hline 263. & 1 & 1 & 1 & 0 & 0 & 1 & 0 \\
\hline 264 . & 1 & 0 & 1 & 0 & 0 & 1 & 1 \\
\hline 265. & 1 & $1 / 4$ & 1 & 0 & 0 & 1 & 1 \\
\hline 266 . & 1 & $1 / 2$ & 1 & 0 & 0 & 1 & 1 \\
\hline 267 . & 1 & $3 / 4$ & 1 & 0 & 0 & 1 & 1 \\
\hline 268 . & 1 & 1 & 1 & 0 & 0 & 1 & 1 \\
\hline 269 . & 1 & 0 & 1 & 0 & 1 & 0 & 0 \\
\hline 270 . & 1 & $1 / 4$ & 1 & 0 & 1 & 0 & 0 \\
\hline 271. & 1 & $1 / 2$ & 1 & 0 & 1 & 0 & 0 \\
\hline 272 . & 1 & $3 / 4$ & 1 & 0 & 1 & 0 & 0 \\
\hline 273. & 1 & 1 & 1 & 0 & 1 & 0 & 0 \\
\hline 274 . & 1 & 0 & 1 & 0 & 1 & 0 & 1 \\
\hline 275 . & 1 & $1 / 4$ & 1 & 0 & 1 & 0 & 1 \\
\hline 276. & 1 & $1 / 2$ & 1 & 0 & 1 & 0 & 1 \\
\hline 277 . & 1 & $3 / 4$ & 1 & 0 & 1 & 0 & 1 \\
\hline 278 . & 1 & 1 & 1 & 0 & 1 & 0 & 1 \\
\hline 279 . & 1 & 0 & 1 & 0 & 1 & 1 & 0 \\
\hline 280. & 1 & $1 / 4$ & 1 & 0 & 1 & 1 & 0 \\
\hline 281 . & 1 & $1 / 2$ & 1 & 0 & 1 & 1 & 0 \\
\hline 282 . & 1 & $3 / 4$ & 1 & 0 & 1 & 1 & 0 \\
\hline 283. & 1 & 1 & 1 & 0 & 1 & 1 & 0 \\
\hline 284 . & 1 & 0 & 1 & 0 & 1 & 1 & 1 \\
\hline 285. & 1 & $1 / 4$ & 1 & 0 & 1 & 1 & 1 \\
\hline 286 . & 1 & $1 / 2$ & 1 & 0 & 1 & 1 & 1 \\
\hline 287 . & 1 & $3 / 4$ & 1 & 0 & 1 & 1 & 1 \\
\hline 288 . & 1 & 1 & 1 & 0 & 1 & 1 & \\
\hline
\end{tabular}

Figure 3. List of possible options for action on levers by the state (a fragment)

Now we proceed to much simpler lists of possible options for action by economic operators and society. The net strategy of economic operators is divided into at least 20 possible options (Figure 4.), and society, apparently - by formula (10) - will have 5 levels of buying goods from official importers.

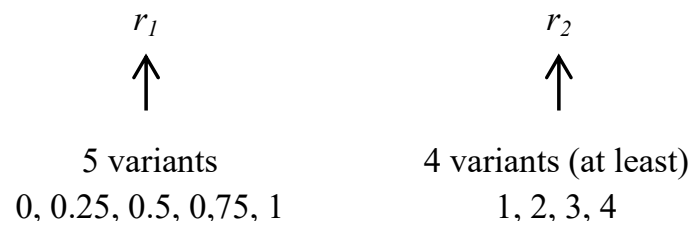

Figure 4. The smallest number of possible options for action on levers by economic operators is equal to $5 \cdot 4=20$
The corresponding numbering, which we will need in the further operation with these strategies, has been completed. 


$\begin{array}{rcc}\text { 1. } & \text { r.1 } & \text { r_2 } \\ \text { 2. } & 0 & 2 \\ \text { 3. } & 0 & 3 \\ \text { 4. } & 0 & 4 \\ \text { 5. } & 1 / 4 & 1 \\ 6 . & 1 / 4 & 2 \\ 7 . & 1 / 4 & 3 \\ \text { 8. } & 1 / 4 & 4 \\ 9 . & 1 / 2 & 1 \\ 10 . & 1 / 2 & 2 \\ 11 . & 1 / 2 & 3 \\ 12 . & 1 / 2 & 4 \\ 13 . & 3 / 4 & 1 \\ 14 . & 3 / 4 & 2 \\ 15 . & 3 / 4 & 3 \\ 16 . & 3 / 4 & 4 \\ 17 . & 1 & 1 \\ 18 . & 1 & 2 \\ 19 . & 1 & 3 \\ 20 . & 1 & 4\end{array}$

Figure 5. List of all 20 (at least) possible options for action on levers by economic operators

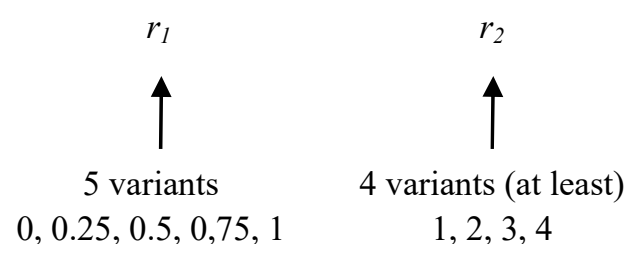

Figure 6. Example of visualization of the three variables function, which values are given in the nodes of a parallelepiped lattice of size $10 \times 7 \times 12$, using colour gradation of these values

The dimensions of the $288 \times 20 \times 5$ parallelepiped "skeleton" (the same for each player's winning function) actually determine the size of the game itself. Strictly speaking, in the corresponding $288 \times 20 \times 5$ non-cooperative game, the state has 80 pure strategies, economic operators have 20 pure strategies, and society has 5 pure strategies according to formula (10). The total number of situations in pure strategies in our game is $288 \times 20 \times 5=28800$, which is, in fact, the number of nodes of the parallelepiped "skeleton". This is an extremely large number of cases for assessing the consequences of the interaction of interests of FEA participants at customs, where a total of $28,800 \times 3=86,400$ cases must be assessed (a number, that is hundreds of times higher than the standard number of cases or situations for expert evaluation or comparison). But we will return to this special and crucial question later.

Thus, with the help of sampling (7) - (10), we made the transition from complex gain functions to gain matrices. This greatly simplifies the presentation (in particular, allows the visualization of winnings as presented in Figure 6.) and work with a game model of interaction of interests of FEA participants at customs. However, it is important to note that these gain matrices are three-dimensional. Therefore, now is the time to complete the final formalization of our game model - to introduce notation for sets of pure strategies and for the matrices of winnings of FEA participants in the corresponding $288 \times 20 \times 5$-noncooperative game.

Our game model of interaction of interests of FEA participants is presented in the form of a $288 \times 20 \times 5$ non-cooperative game, which is denoted as follows:

$$
\Gamma=\left\langle\left\{G_{D}, G_{R}, G_{s}\right\},\left\{\mathbf{M}_{\mathrm{D}}, \mathbf{M}_{\mathrm{R}}, \mathbf{M}_{\mathrm{s}}\right\}\right\rangle .
$$

where $G_{\mathrm{D}}, G_{\mathrm{R}}, G_{\mathrm{s}}$ and $\mathbf{M}_{\mathrm{D}}, \mathbf{M}_{\mathrm{R}}, \mathbf{M}_{\mathrm{s}}$ - sets of pure strategies and three-dimensional matrices (in this case - the size of $288 \times 20 \times 5$ ) gains, respectively, a state, economic operators and society.

Set $G_{\mathrm{D}}$ consists of pure strategies of a state (1), which are discretized by (7) and (8) to 288 possible options for action on levers by the state. These 288 possible variants actually represent the set $G_{\mathrm{D}}$ in the "expanded" (linear) form, which is presented in Figure 3. Set $G_{\mathrm{R}}$ consists of pure strategies of economic operators (4); these strategies are discretized by (9) to at least 20 possible options for action on levers by economic operators (the list is presented in Figure 5.). A set of these 20 possible options forms an "expanded" view of the set $G_{\mathrm{R}}$ The set $G_{\mathrm{s}}$ consists only of values in the formula (10), that is: $G_{s}=\{0,0.25,0.5,0.75,1\}$.

The "expanded" representation of this set is surprisingly obvious and easy.

Elements of three-dimensional matrices of gains of a state, economic operators and society are denoted as follows:

$$
\begin{aligned}
& \mathbf{M}_{\mathrm{D}}=\left(\delta_{i j k}\right)_{288 \times 20 \times 5}, \\
& \mathbf{M}_{\mathrm{R}}=\left(\rho_{i j k}\right)_{288 \times 20 \times 5}, \\
& \mathbf{M}_{\mathrm{s}}=\left(\sigma_{i j k}\right)_{288 \times 20 \times 5},
\end{aligned}
$$

where the indices $i, j$ and $k$ mean the situation in the game (11) formed by $i$-th, $j$-th and $k$-th net strategies of a state, economic operators and society, respectively. Values $\delta_{i j k}, \rho_{i j k}$ and $\sigma_{i j k}$ are appropriate gains in this situation.

Obviously, by "winning" we do not mean the result of a lottery or a draw. As in classical game theory, the gains of a state, economic operators and society in a non-cooperative game (11) are equal to or proportional to certain benefits obtained in a particular model game situation. These benefits in a situation $\{i, j, k\}$ are equal accordingly $\delta_{i j k}, \rho_{i j k}$ and $\sigma_{i j k}$, but so far we have not decided on units of their measurement.

For different economic problems, units of measurement of benefits (usefulness) can be chosen differently, taking into account both specific needs of stakeholders and economic nature of parties themselves (products they produce, goals to control profitability, investment attractiveness, advertising, 
import / exports restrictions, etc.). We have three participants in foreign economic activity, which usefulness cannot be measured in the same way. Therefore, it is absolutely logical to choose standardized and dimensionless units. Moreover, in the same way we have already constructed the strategies of FEA participants. In this case, we will be able to directly compare the consequences of the interaction of interests of FEA participants at customs.

Thus, we put the value of the winnings of FEA participants at customs in the game model of interaction of their interests in the range from 0 to 1 . This is a common practice in the vast majority of economic problems, which must take into account diverse interests. A value of 0 will correspond to the lowest relative usefulness, and 1 - the highest one.

The next task is to find such situation(s) in the game (11), which would be beneficial for a state, economic operators and society. In other words, we will solve the game (11), the matrix of players' winnings (12). First, we find all equilibrium strategies, where by equilibrium we mean the classical Nash equilibrium - the situation $\left\{i^{*}, j^{*}, k^{*}\right\}$ in the game (11) is Nash equilibrium if in relation to any situation $\{i, j, k\}$ three inequalities are simultaneously satisfied:

$$
\begin{aligned}
& \delta_{i j k} \leq \delta_{i^{*} j^{*} k^{*}}, \rho_{i j k} \leq \rho_{i^{*} j^{*}} k^{*}, \sigma_{i j k} \leq \sigma_{i^{*} j^{*} k^{*}} \\
& \text { for all } i=\overline{1,288}, j=\overline{1,20}, k=\overline{1,5} . .
\end{aligned}
$$

Situations in index numbering $\{i, j, k\}$ and $\left\{i^{*}, j^{*}, k^{*}\right\}$ mean situations (in letter notation):

$\left\{d_{1}, d_{2}, d_{3}, d_{4}, d_{5}, d_{6}, d_{7}, r_{1}, r_{2}, s\right\}$ та

$\left\{d_{1}^{*}, d_{2}^{*}, d_{3}^{*}, d_{4}^{*}, d_{5}^{*}, d_{6}^{*}, d_{7}^{*}, r_{1}^{*}, r_{2}^{*}, s^{*}\right\}$.

As it turned out, there are only three equilibrium situations in this game. In these situations, a state's contingent usefulness is remarkably stable (Table 1.).

\begin{tabular}{|c|c|c|c|c|c|c|c|c|c|c|c|c|}
\hline 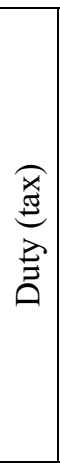 & 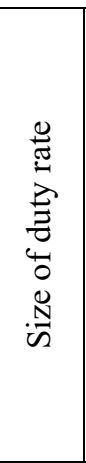 & 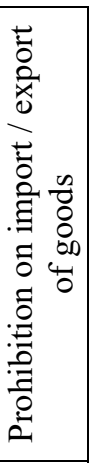 & 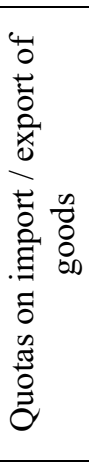 & 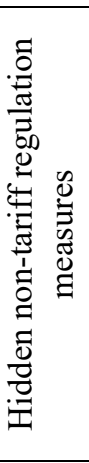 & 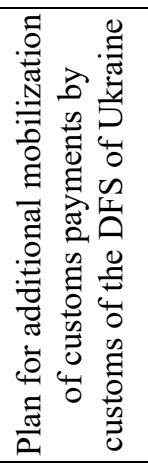 & 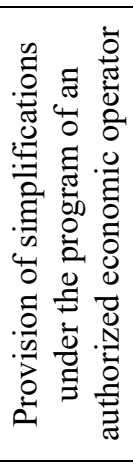 & 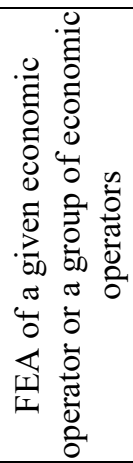 & 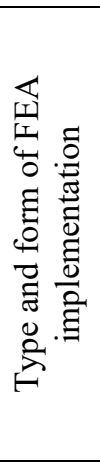 & 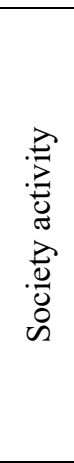 & 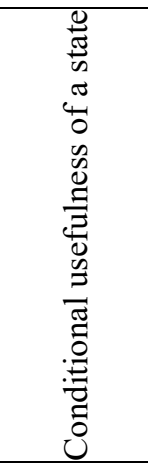 & 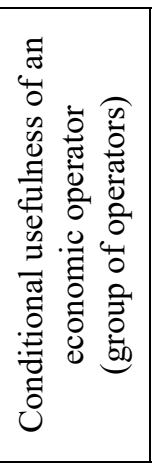 & 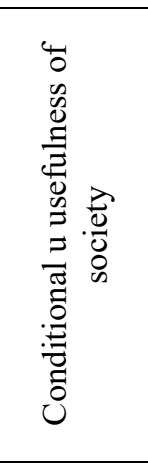 \\
\hline$d_{1}$ & $d_{2}$ & $d_{3}$ & $d_{4}$ & $d_{5}$ & $d_{6}$ & $d_{7}$ & $r_{1}$ & $r_{2}$ & $s$ & $\delta_{i^{*} j^{*} k^{*}}$ & $\rho_{i^{*} j^{*} k^{*}}$ & $\sigma_{i^{*} j^{*} k^{*}}$ \\
\hline 1 & 1 & 0 & 1 & 1 & 1 & 0 & 1 & 2 & 1 & 0.641748 & 0.008861 & 0.008707 \\
\hline 1 & 0.5 & $\mathbf{0}$ & 1 & 1 & 1 & 1 & 1 & 4 & 0.75 & 0.641832 & 0.961834 & 0.007809 \\
\hline 1 & 0.75 & 0 & 1 & 1 & 1 & 1 & 1 & 1 & 0.75 & 0.640372 & 0.500507 & 0.008582 \\
\hline
\end{tabular}

Table 1. The list of options for actions of FEA participants and their results in Nash equilibrium situations for in the game

As we can see, the second situation in Table 1. (highlighted in bold) is the most favourable for both the state and economic operators. However, at the same time this situation is extremely unfavourable for society. However, in the other two situations, society will benefit too little.

\section{Conclusions}

The realities of modern development of socioeconomic processes in a digital economy and the constant transformation of international trade necessitate the search for management tools that would meet requirements of the time and allow reasonable strategic decisions. The study proposes to use game theory for this purpose, as well as formed a game model that takes into account the balance of interests of major market players. This game model includes three main participants in economic relations: state, economic operators, society. The study concludes that the state has 80 pure strategies, economic operators have 20 pure strategies, and society has 5 pure strategies. The results of the game allow to determine the most favourable situation for the state and for economic operators, which ensures the balance of interests of the represented entities.

Thus, from the standpoint of regulating international trade, the issues of forming a balance of interests of all participants in this process allow to obtain positive results not only for specific business entities, but also for society as a whole. These issues become especially important in the context of further growth of e-commerce, which leads to new forms of development of the digital economy, and also create new scientific problems for further research. 


\section{References}

[1]. Campbell, D. T. (1965). Ethnocentric and other altruistic motives. In Nebraska symposium on motivation (Vol. 13, pp. 283-311).

[2]. Illiashenko, O., Rudnichenko, Y., Momot, T., \& Havlovska, N. (2020). The Enterprise Economic Security System: The State Assessment Using Management Functional Types. International Journal for Quality Research, 14(1).

[3]. Kopytko, M. I., Levkiv, G. Y., \& Vinichuk, M. V. (2018). Macroeconomic security of ukraine: Problematic aspect of research and prospects of strengthening. Journal of Automation and Information Sciences, 50(2), 62-70.

[4]. Nash, J. (1951). Non-cooperative games. Annals of mathematics, 286-295.

[5]. Nash, J. F., Nagel, R., Ockenfels, A., \& Selten, R. (2012). The agencies method for coalition formation in experimental games. Proceedings of the National Academy of Sciences, 109(50), 20358-20363.

[6]. Pareto, V. (1896). Cours d'économie politique: professé à l'Universi̧té de Lausanne (Vol. 1). F. Rouge.

[7]. Pareto, V. (1964). 1897: Cours d'économie politique, 2 vols, ed. G. H. Bousquet and G. Busino. Geneva: Librairie Droz.
[8]. Pareto, Y. (1961). On the equilibrium of social systems. Theories of Society; Foundations of Modem Sociological Theory, 2, 1288-1291.

[9]. Pratto, F., Sidanius, J., \& Levin, S. (2006). Social dominance theory and the dynamics of intergroup relations: Taking stock and looking forward. European review of social psychology, 17(1), 271-320.

[10]. Romanuke, V. (2016). Evaluation of Payoff Matrices for Non-Cooperative Games via Processing Binary Expert Estimations. Information Technology and Management Science, 19(1), 10-15.

[11]. Rudnichenko, Y., Havlovska, N., Melnyk, S., Illiashenko, O., \& Nakonechna, N. (2021). Strategic interaction of state institutions and enterprises with economic security positions in digital economy. Wseas transactions on business and economics, 18, 218-230.

[12]. Siroën, J. M. (2004). L'international n'est pas le global: Pour un usage raisonné du concept de globalisation. Revue d'économie politique, 681-698.

[13]. Thakur, R. (2013). Balance of Interests in Oxford Handbook of Modem Diplomacy. A. F. Cooper, J. Heine and R. Thakur. Oxford: Oxford University Press.

[14]. Vorobyov, N.N. (1985). Game Theory for Economists-Cybernetics. Moscow: Science.

[15]. Young, H. P., \& Zamir, S. (2015). Handbook of game theory with economic applications (Vol. 4). Elsevier. 